\title{
GI-MS45-01 | FIGHTING THE WIND MILLS: ARE CRYSTALLOGRAPHERS THE SUCCESSORS OF DON QUIXOTE?
}

Nespolo, Massimo (Université de Lorraine, Vandoeuvre-lès-Nancy, FRA)

Crystallography is a perfect candidate to represent the popular adagio "victim of its success". Everybody agrees that the contribution of crystallographers to a wide range of disciplines is of paramount importance, yet lectures specifically devoted to crystallography are becoming an endangered species, and open positions for crystallography as rare as unicorns. The consequences of this pernicious choice are multiple, including the frequent occurrence of sloppy, if not fundamentally incorrect, statements in the literature, and the huge difficulties experimentalists meet to find answers to practical problems which would not be an obstacle had they received a solid crystallographic education. An increasing demand for intensive lectures and short courses has arisen in the last twenty years, to which the IUCr commissions have responded with tireless efforts. In this talk I will report about my personal experience as lecturer in tens of international schools around the world, which have been occasion to meet colleagues working in different fields and start collaborations which have taken advantage of the respective knowledge and expertise. In particular, I will emphasize the striking contrast between the reluctance of crystallographers to identify themselves as such and the request for crystallographers as lecturers in research facilities and Universities. 